\title{
UMA LEITURA DO ROMANCE ENSAIO SOBRE A CEGUEIRA SOB O OLHAR DA FENOMENOLOGIA
}

\author{
Maria Ivonete Coutinho da SILVA \\ Campus Universitário de Altamiraf-a \\ ivonet@ufpa.br
}

\begin{abstract}
Resumo: Este trabalho tem como objeto de estudo o romance Ensaio sobre a cegueira de José Saramago, com o objetivo de questionar e refletir sobre a existência humana e suas relações de identidade/alteridade no âmbito do contexto pós-moderno. A análise sobre o olhar versus cegueira se fundamenta nas concepções filosóficas, com ênfase no olhar fenomenológico discutido por Maurice Merleau-Ponty que o situa no campo da percepção. Este redimensionamento do olhar para o campo da percepção traz em seu bojo, outra concepção de vida e de existência que permite ampliar o horizonte das experiências vividas, possibilitando o encontro com o outro. Através da cegueira, como metáfora da visão, propomos perfilhar este caminho, em busca de um olhar que não só desvende o mundo, mas que revele a nós e aos outros.
\end{abstract}

Palavras-chaves: Cegueira. Olhar fenomenológico. Percepção. Ver.

Abstract: This work has as study object the romance Assay on the blindness of Jose Saramago, with the objective to question and to reflect about the existence human being and its relations of identity/alterity in the scope of the context after-modern. The analysis on the look versus blindness is based on the philosophical conceptions, with emphasis in the phenomenological look argued by Maurice Merleau-Ponty that points out it in the field of the perception. This resizing of the look for the field of the perception brings in its bulge, another conception of life and existence that allows to extend the horizon of the lived experiences, making possible the meeting with the other. Through the blindness, as metaphor of the vision, we consider to adopt this way, in search of a look that not only unmasks the world, but that it discloses we and the others.

Keywords: Blindness. Phenomenological look. Perception. Learning.

O mérito da nova filosofia é de procurar na noção de existência o método que faz pensar. A existência no sentido moderno, é o movimento pelo qual o homem é um ser no mundo, engaja-se numa situação física e social que constitui seu ponto de vista sobre o mundo.

Merleau-Ponty.

O presente texto é decorrente da minha dissertação de mestrado (2003) ${ }^{1}$ a qual analisou o romance Ensaio sobre a cegueira $(E S C)$ do escritor português José Saramago, sob a luz das teorias filosóficas, antropológicas e literárias. Este romance já foi abordado sob diversos aspectos, e como toda boa literatura é uma fonte inesgotável de perguntas e respostas. Uma das principais articulações e discussões que este texto possibilita é a reflexão sobre o olhar na contemporaneidade. O olhar está no centro dos debates nos dias atuais.

\footnotetext{
${ }^{1}$ Ensaio sobre a cegueira: um olhar que transcende o olho (2003). Universidade Federal de Pernambuco-UFPE.
} 
Vivemos no mundo do ver, onde tudo está ex-posto para ser visto. Mas nesse mundo, o que é olhar? O que é ver? O que é ser visto?

Esta reflexão parte das inquietações que emergem da tessitura do romance e as redimensiona para um campo onde a cegueira pode ser lida como metáfora da descoberta da visão. Nesta perspectiva, este texto objetiva levantar uma discussão e a reflexão sobre o olhar no mundo contemporâneo, onde tudo é programado para ser imagens e signos. Neste cenário, não se exige mais dos signos que tenham algum contato verificável com o mundo que supostamente representam. Jean Baudrillard ${ }^{2}$, diz que no regime de simulação característico da sociedade contemporânea, o poder e tudo mais são moldados em signos de aparências e são distribuídos de modo uniforme, contrariando todos os antagonismos reais e dicotomias de valor. A simulação é o processo pelo qual a representação da realidade adquire valor de verdade.

Em contrapartida este trabalho procura questionar e refletir sobre que a cegueira descrita no romance, como um artifício que pode transcender os limites visuais, impostos pela sociedade da imagem e se estender para um mundo onde o visível e o invisível, são moldados no sensível. Esta discussão se fundamenta na fenomenologia da percepção defendida por Maurice Merleau-Ponty (1994), que nos convida a redescobrir a esfera do sensível, mostrando que há uma universalidade do sentir e é sobre ela que repousa nossa identificação, a constituição do eu, a generalização do corpo e a percepção do outro. Portanto, para ele, "todo o saber se instala no horizonte da percepção."3

A narrativa relata a história de uma cidade acometida por uma epidemia de cegueira tenebrosa e repentina. Um homem comum, num dia comum, está parado no sinal de trânsito com seu carro à espera que este abra. Ao tentar dar partida no veículo, percebe que está cego. Os habitantes da cidade, um após outro vão perdendo a visão, no trânsito, no trabalho, em casa e por fim, toda a população é atingida pela cegueira. Sem motivos que se entenda ou razão que se explique, são confinados e excluídos. Este fato inusitado e inexplicável gera um caos social que nos leva a refletir não apenas sobre o olhar e/ou a cegueira, mas sobre a condição humana no mundo contemporâneo.

\footnotetext{
${ }^{2}$ Apud, CONNOR, Steven. Cultura Pós-moderna: introdução às teorias do contemporâneo. São Paulo: Edições Loyola, 1993. p. 51.

${ }^{3}$ Maurice Merleau-Ponty interage com a corrente fenomenológica de Husserl, cujo lema máximo era a 'volta às coisas mesmas'. Pelo viés da redução fenomenológica, desenvolve outra concepção da fenomenologia, tendo como ponto de partida o retorno ao mundo, onde não há ruptura entre o vivido e o pensado. MERLEAUPONTY, Maurice. Fenomenologia da Percepção. Martins Fontes. 1994. p. 260ss
} 
Neste romance o homem é pensado em seu meio natural, cultural e histórico, cuja vivência parte do contexto social no qual está inserido. Assim, sob o olhar da fenomenologia, a cegueira e o olhar são colocados em questão, considerando as realidades vividas por cada personagem. Neste sentido, a cegueira se desdobra como uma dolorosa experiência do reaprendizado do olhar e desse modo comunga com o pensamento filosófico de Merleau-Ponty que diz: "o mundo é o que vemos e, contudo, precisamos a prender a vê-lo."4

A história da filosofia tem nos mostrado que a discussão sobre o olhar no ocidente remonta desde a Antiguidade. Este olhar como metáfora do saber é discutido, de Platão a Descartes que o reduzirá a metáfora do conhecimento científico. Tanto em Platão como em Aristóteles, a busca do saber e da verdade fundamenta-se na metafísica do olhar como ato de contemplação, sendo esta uma atividade reservada ao domínio do inteligível.

Com Descartes, é a luz da razão que ilumina as coisas e, a partir daí inaugura-se uma nova relação sujeito-objeto, ver-visto, determinando outra concepção não só do conhecimento, mas também do visível. É a fenomenologia que retomará as questões concernentes ao mundo visível, com Husserl e principalmente com Merleau-Ponty, nas obras O visível e o invisível (2000) e a Fenomenologia da percepção (1994).

Observamos que as várias abordagens filosóficas sobre o olhar diferem de acordo com as concepções de homem de cada época, no entanto, todas estão ligadas à questão do conhecimento, do homem versus mundo. Embora andem por caminhos diferentes, as diversas correntes de pensamento têm em comum o olhar como fonte do saber.

Assim como o olhar é tema recorrente entre os filósofos, o seu contraponto, a cegueira, também é abordada metaforicamente por diversos teóricos, tornando-se mito universal na famosa alegoria da Caverna de Platão. Ele descreve o estado inicial de ignorância dos homens que acreditavam serem verdadeiras as sombras projetadas pelo fogo sobre a parede de uma caverna onde estavam presos. Um dos homens que ali vivia consegue se libertar e sai da caverna; no momento em que olha para luz do sol, sua visão fica ofuscada, tornando-o incapaz de ver os objetos cujas sombras antes ele via como se fosse a própria realidade.

Esse mito, marca a passagem de um mundo no qual o sujeito inicialmente percebe os objetos num jogo de luz e sombra e, em seguida caminha da escuridão para claridade, das

\footnotetext{
${ }^{4}$ MERLEAU-PONTY, M. O Visível e o Invisível. São Paulo: Editora Perspectiva, 2000.
} 
trevas para o sol, da cegueira para o deslumbramento, ou seja, para a verdade. Esse mito é um artifício que torna explícito a separação do mundo sensível com o mundo inteligível, o mundo sensível é um simulacro onde as imagens substituem o real, nele a visão está limitada à realidade aparente. A realidade deve se adequar à Idéia, à constatação inteligível dela.

Esta Idéia de realidade configura-se no romance em estudo. Assim como o homem da caverna, que vivia num mundo de aparência, as personagens do romance também estão inseridas num contexto social impregnado de imagens superficiais e simuladas, no qual os valores materialista e individualista e, sobretudo o avanço da ciência tecnológica, leva o indivíduo ao excesso de visibilidade e conseqüentemente, à cegueira coletiva.

No filme Janela da Alma, de João Jardim e Walter Carvalho, Saramago diz que a sociedade atual, mais do que nunca, representa a caverna de Platão. Ele diz que passaram séculos e séculos para que a alegoria da caverna se situasse no contexto real.

Na sociedade atual os olhos perderam a sua função originária sendo substituída pela visão técnico-cientificista. Vivemos num mundo de imagens superficiais e aparentes, onde o verdadeiro sentido da existência é absorvido pelo espetáculo das imagens visuais, que não possibilitam reconhecer a si mesmo, menos ainda, perceber a existência do outro.

Merleau-Ponty (2000) contesta esta visão cientificista do olhar, ao afirmar que a experiência sensível fornece fundamentos para a criação do conhecimento e pode assim revelar a cegueira da consciência. Para ele, é no campo dos sentidos que se inscreve o ato de ver, "É preciso que nos habituemos a pensar que todo visível é moldado no sensível, todo ser táctil está voltado de alguma maneira à visibilidade."5

Dessa forma, se contrapõe à tradição filosófica que concebe a Idéia como fonte de conhecimento e, sobretudo, a Descartes que preconizava a cisão entre espírito e corpo, ficando a ordem do visível submetida ao domínio da ciência. Para Merleau-Ponty a filosofia como busca da verdade consiste em aprender a ver o mundo, descobrir seu sentido tanto na história decorrida quanto no tempo presente.

Feito esse breve percurso em torno do olhar e da cegueira na trajetória filosófica, entendemos que a visão depende de nós e se origina em nossos olhos, mas vai além deles. Para que se possa ver melhor a si mesmo, é necessário estender o olhar para o outro, para a diferença, já que toda tomada de consciência consiste no crescimento do ser e no reconhecimento do olhar do outro sobre si, envolvendo ambos em um 'único mundo' como

\footnotetext{
${ }^{5}$ MERLEAU-PONTY, Maurice. O Visível e o Invisível. Op. cit. p. 131.
} 
fenômeno da percepção, como nos mostra o contexto ficcional. "[...] Também não nos surpreenderá que busquem todos estar juntos o mais possível, há aqui muitas afinidades, umas que já são conhecidas, outras que aos poucos se revelarão (ESC. p. 67).

A descoberta dessa visão perceptiva implica não somente na relação de descoberta da corporeidade individual, mas se estende para as experiências de intercorporeidade como uma dimensão da co-existência na qual a minha perspectiva e a do outro se encontram, confluindo para outras aberturas. Neste sentido Merleau-Ponty (1994), adverte que para apreender esta ampla dimensão das relações humanas, faz-se necessário um ressurgir de si mesmo e desmascarar a razão instrumental e objetivante que possibilita a cegueira e a morte, como nos diz a passagem; “[...] mais necessidades teriam os que estão vivos de ressurgir de si mesmos, e não o fazem, parecem que já estão meio mortos” (ESC. p, 288).

Essa consciência de ser-no-mundo não ocorre por acaso, é o que desde sempre somos. No entanto, nem sempre o homem se apercebe disto, disperso no cotidiano, perde esta dimensão caindo no vazio de si mesmo e das relações. É necessário um processo de ruptura, como por exemplo, o da cegueira, para que a consciência de ser-no-mundo se manifeste o que ocorre após um aprendizado constante, que se dá no dia a dia, no fluxo da vida chamada existência onde a própria vida é redimensionada.

Assim, a cegueira no contexto do romance, não pode ser lida apenas como uma anulação total do mundo, mas como um recuo, um distanciamento desse mundo labiríntico para melhor compreendê-lo. Talvez por isso, os cegos não são poupados em nada em suas vivências cotidianas, inclusive, quando são enviados para o manicômio, este recinto, não recebe nenhum cuidado especial para acolhê-los.

Ali são obrigados a conviver numa comunidade de cegos, procurando se adaptar a um ambiente fechado e caótico, "que começa não se sabe porquê e acaba não se sabe onde. Duzentas pessoas não se arrumam com essa facilidade, de mais a mais cegas e sem guia, acrescendo o fato de se encontrarem num edifício antigo, de distribuição pouco funcional" (ESC. p.112). Aos poucos eles vão assimilando com as dificuldades, as novas regras de convivência, de modo que possam garantir a sobrevivência naquele lugar de cegos.

Neste lugar prevaleciam todos os pré-conceitos que antes norteavam o mundo visível, (o poder, individualismo, materialismo, ganância, a possessividade nas relações afetivas...) enfim, todos os valores e des-valores que constituem a sociedade dos que 'vêem'. Consciente, talvez desta realidade, a mulher do médico diz: "O mundo está todo aqui dentro" (ESC. p. 
102). Ali, em processo de adaptação e de descobertas do espaço físico como também do outro, o limite do horizonte visual situa-se no encontro direto, na corporeidade. Impreterivelmente, é preciso compreender que “o olhar não está isolado, ele está enraizado na corporeidade enquanto sensibilidade e enquanto motrocidade." 6

Para que os cegos chegassem a este entendimento, não faltaram lutas corporais e confrontos de idéias. Era de se esperar, comenta o narrador deste romance, induzindo à conclusão de que a regra geral da humanidade sempre foi à luta, assim só resta dizer: “[...] lutar sempre foi mais ou menos uma forma de cegueira" (ESC. p.135). A passagem abaixo nos descreve um desses momentos de luta corporal, no espaço real e simbólico da quarentena, lugar onde os cegos passaram a viver.

[...] Mais tarde ou mais cedo, com jeito e paciência, os novos hóspedes acabarão por acomodar-se, porém não antes que se decida a batalha que acabou de travar-se entre as primeiras linhas da coluna da esquerda e os contaminados do lado direito (ESC. p.112).

No intervalo da cegueira, entre o olho que não pode ou não quer mais ver e o olhar que vai além do banal ao qual tudo se nivela, a dimensão do olhar fenomenológico revelará um outro enfoque de visão que se manifesta como uma forma de apreensão do mundo pelo movimento perceptivo. Reconhecendo que somos plenamente visíveis para nós mesmos graças aos olhos dos outros, como diz a mulher do médico: "[...] cada vez irei vendo menos, mesmo que não perca a vista tornar-me-ei mais e mais cega a cada dia porque não terei quem me veja" (ESC. P. 302).

Este processo de reversibilidade do ver e ser-visto pelo olhar do outro, implica a compreensão de que ver e olhar estão num mesmo contexto de co-existência. Para MerleauPonty, não há um distanciamento entre aquele que olha e o mundo visto. O ver vai além do visível e retoma a origem do ser, para melhor situar o sujeito no mundo e compreender sua relação com o outro e consigo mesmo. Esta relação é mediada pela presença do corpo enquanto objeto que o outro vê e encontra, nele, um campo aberto de experiências visíveis e invisíveis, "[...] o corpo é o nosso meio geral de ter um mundo."7

O olhar fenomenológico aponta para o questionamento daquilo que antes víamos, interrogando-nos se esta visão não é apenas fruto da subjetividade ou do excesso da racionalidade instrumental.

\footnotetext{
${ }^{6}$ BOSI, Alfredo. Fenomenologia do olhar. In: O Olhar. Op. cit. p.66.

${ }^{7}$ MERLEAU-PONTY, Maurice. Fenomenologia da Percepção. Op. cit. p. 233.
} 
O homem que aprendeu a olhar desconfia da percepção imediata, quase sempre ilusória e relativa comparando-a a outras formas de percepção, que dão do mesmo objeto uma visão diferente. Ele opõe a visão etnocêntrica de um olhar ingênuo, que transforma em absolutos os valores e instituições de sua própria cultura, a percepção por assim dizer etnográfica de um olhar que passou pela pedagogia da diferença e do pluralismo. ${ }^{8}$

Sob esta visão o mundo é o âmbito em que se vive, é aquilo que se percebe e ver, enquanto experiências vividas. Seja num quarto de hotel, na hora do amor/desejo de uma prostituta, em um lapso de desonestidade, o caso do ladrão que estava a roubar um carro, seja na seriedade da profissão, quando o médico oftalmologista pesquisava a respeito de uma cegueira estranha, e, sobretudo, no caso do primeiro cego, que ao gritar em pleno palco citadino, 'estou cego' iniciava a trajetória filosófica da cegueira e/ou do olhar, a partir do contexto ficcional.

Esta leitura é possível quando se analisa a cegueira como uma metáfora, pela qual se faz um recuo do mundo visível para melhor compreendê-lo e redescobrir nele as experiências vividas a partir da interrogação, da dúvida e das abstrações filosóficas necessárias. A cegueira neste contexto se impõe como uma negação de tudo que representa e estrutura o mundo visível, inclusive os valores que antes norteavam aquela sociedade, e se configura como um exercício de re-aprender a ver o mundo.

Diante desta realidade de negatividade, (ou de cegueira) em que estão ocultas as coisas e os seres, é preciso redescobrir outras formas de interação com o mundo, como também reconhecer que a vivência humana se dá como um jogo de luz e sombra e por isso, a cegueira pode ser concebida como um momento de sombra, que como um nevoeiro tenebroso, urge ser transposto para que se possa ver o mundo como um todo.

Este processo de descobertas do ponto de vista fenomenológico pode ser uma ponte para a transgressão da cegueira luminosa, desconcertante e inexplicável. Merleau-Ponty (2000) ao voltar-se para o homem como ser-no-mundo, não se afasta da ciência, ao contrário, fundamenta-a por saber que esta é capaz de esclarecer as diversas experiências humanas e ao mesmo tempo revelar os caminhos que levam a transcender as situações de cegueira.

Ver é tocar à distância e essa visão permite abrirmos para a textura do mundo que nos envolve. Um mundo que na sua profundidade desconhece a dicotomia visível-invisível

\footnotetext{
${ }^{8}$ ROUANET, Sérgio Paulo. O Olhar Iluminista. In: O Olhar. Op. cit. p.135.
} 
conforme nos propõe Merleau-Ponty. ${ }^{9}$ Esta assertiva articula-se ao propósito deste trabalho, o qual apresenta a cegueira como um desafio que pode ser explicitado sob duas perspectivas distintas.

A primeira parte de uma cegueira que veio para desestruturar e fragmentar todas as referências identitárias de uma sociedade: nome, família, casamento, casa, estruturas públicas e privadas. Outra que se fundamenta no olhar perceptivo e intencional, que visa o fenômeno em sua totalidade. Assim, o fenômeno da cegueira é descrito englobando sujeito e objeto, no qual as atitudes subjetivas e objetivas rompem com a dicotomia racionalista que se impõe entre a identidade/alteridade.

Nesta perspectiva a trajetória pela cegueira conduz a descentralização do olhar forçando os cegos a buscarem outras formas de compreensão do mundo. Esta experiência vai se desenvolvendo com a descoberta da corporeidade, pois com a perda da visão, a percepção das coisas e dos seres passa inevitavelmente por outros sentidos, principalmente pela percepção táctil, ou seja, pelo fenômeno da percepção.

\subsection{Da vivência do espaço à experiência da corporeidade}

A exterioridade do corpo é figura concentrada de poder. Nele, a vontade se isola e se individualiza e por ele faço a experiência do que me pertence. Nele o passado aflora no presente, nele se realiza o aqui e o agora. Nele se desenvolve o drama do personalizar-se de cada individuo.

Arcângelo Buzzi

Nesta discussão o espaço enquanto ambiente físico se estende para uma reflexão de espacialidade que estabelece fronteiras e institui referências identitárias, através do movimento e da expressão corporal. Esta reflexão se fundamenta na "fenomenologia da percepção" de Merleau-Ponty (1994) na qual o contorno do corpo é uma fronteira que estabelece relações com o espaço ordinário, mas o transcende. Neste sentido a percepção do mundo e da história dos homens se dá pela articulação do sujeito com o espaço táctil, “já que o mesmo corpo vê e toca, o visível e o tangível pertencem ao mesmo mundo." 10 Como diz o narrador do romance: "não é preciso ter olhos para saber de que lado está a mão direita" (ESC. p. 104).

\footnotetext{
${ }^{9}$ Este projeto filosófico, centrado na percepção, perpassa toda a obra de Merleau-Ponty, mas é nas duas obras citadas, Fenomenologia da percepção, obra prima, e $\mathbf{O}$ Visível e o invisível onde está esboçada com mais clareza.

${ }^{10}$ Ibidem, Op. cit. p.131.
} 
Este espaço, compreendido como lugar de co-existência, de relações de intercorporeidade, pode ser verificado no contexto ficcional de (ESC) a partir de dois lugares distintos e adversos. O primeiro é um manicômio, lugar pouco aceitável no contexto social pelo objetivo a que se destina. É categoricamente o lugar do Outro, ou seja, do louco, do anormal, do excluído e no contexto romance, lugar destinado aos cegos. O segundo espaço é a casa, considerada em sua origem, como imagem da intimidade repousante, seja templo, palácio ou cabana. No entanto, esta concepção de casa se coloca à margem, visto que uma outra realidade se impõe, quando os cegos perdem as referências da casa de morada. As casas são abandonadas por uns e invadidas por outros.

O manicômio, lugar destinado às vítimas da epidemia de cegueira, está a muito abandonado e permanece com a mesma estrutura de organização que tinha para 'comportar' os loucos. Agora, será destinado a receber um outro tipo de excluído do meio social: os cegos. Lá são jogados sem que este ambiente passe por nenhuma mudança para recebê-los na condição de cegueira em que se encontram.

A mulher guiava o marido para camarata. Era comprida como uma enfermaria antiga, com duas filas de camas. [...] havia mais caramatas, corredores longos e estreitos, gabinetes que deviam ser de médicos, sentinas encardidas, uma cozinha que não perdera o cheiro de má comida, um refeitório com mesas de zinco, três celas até a altura de dois metros e forrada de cortiça. Por trás do edifício havia uma cerca abandonada, com árvores mal cuidadas. Por toda parte havia lixo (ESC. p. 47).

Neste espaço ‘estranho' onde muitos cegos passam a viver, se impõe a necessidade de compreender e assimilar as mais diversas situações que surgem. Eles são obrigados a compartilhar com outros, experiências que antes eram tidas como particulares, como por exemplo, as necessidades fisiológicas.

Naquele espaço, todos os cantos e recantos eram coletivos. As camas são distribuídas paralelamente, a comida é repartida por grupos, os sanitários são comuns para homens e mulheres. Dessa forma o manicômio se caracteriza como um indiviso, no qual se impõe necessariamente o encontro e/ou desencontro com o outro. Neste lugar a vida precisa ser resignificada para que continuem a existir e exige um maior aprofundamento quanto à relação do espaço e as experiências de corporeidade que os envolvem.

É através do corpo que os cegos re-estabelecem o contato com o outro e com o mundo. A dimensão do espaço é, na obra de Merleau-Ponty (1994), visto desde um prisma ontológico. Este, não é apenas um lugar onde o homem por hora habita, mas, lugar de experiência, de relações, onde o homem se constitui enquanto ser-no-mundo. 
No livro Não-lugares ${ }^{11}$, Marc Augé analisa a relação do homem com o espaço, a questão da identidade e da coletividade. Ele faz uma abordagem sócio-cultural da pósmodernidade a partir das relações entre espaço e alteridade, que se evidenciam em situações de não-lugares nos quais, as contradições da sociedade contemporânea se manifestam através de três imagens de excesso: o excesso de tempo, excesso de espaço e o excesso de individualismo.

Lugares e não-lugares correspondem aos espaços concretos, mas também a atitudes, a posturas, a relações que os indivíduos entretecem com os espaços onde eles vivem ou percorrem $^{12}$. Deste ponto de vista, o sentido do não-lugar está relacionado com a intersubjetividade, como também, se articula com a situação de instabilidade, com a ausência de marcadores referenciais de lugar.

Articulado ao romance tanto o manicômio como a cidade, se evidencia como nãolugares, onde os cegos não podiam contar com as referências anteriores do lugar antropológico, ou seja, o espaço cultural temporalmente definido. A estada nestes lugares se caracteriza com uma situação provisória, um rito de passagem, como é expresso no texto: “[...] estou de passagem, dissera o escritor e estes são os sinais que ia deixando ao passar". (ESC. p. 279).

No início da convivência no manicômio, os cegos comportam-se como se temessem dar-se a conhecer um ao outro, conforme observa a mulher do médico. No entanto, com o passar dos dias, compreendem que é preciso criar vínculos de convivência, de afetividade. Cada um sente no corpo a necessidade deste contato mais direto com o outro. Não é por acaso que dois cegos se encontram e se amam ou que a rapariga de óculos escuros se coloca debaixo da coberta do velho da venda preta, que o menino estrábico busca aconchego nos braços da mulher do médico e assim por diante.

Os cegos também sentem necessidade de estabelecer relações mais duradouras e confiáveis. Buscam conhecer mais profundamente um ao outro. Além de conhecerem a história de cada um e de como cegara, procuram criar meios de convivência que possa garantir-lhes um ambiente menos degradante e mais humano.

Quanto a primeira camarata, talvez por ser a mais antiga, e portanto, estar a mais tempo em processo de seguimento de adaptação do estado de

\footnotetext{
${ }^{11}$ Cf. AUGÉ, Marc. Não-Lugares: introdução a uma antropologia da supermodernidade. São Paulo: Papirus, 1994.

${ }^{12}$ AUGÉ, Marc. O Sentido dos Outros: atualidade da antropologia. Petrópolis: Vozes, 1999. p. 71ss
} 
cegueira, um quarto de hora depois de os seus ocupantes terem acabados de comer, já não havia um papel sujo no chão, tudo havia sido recolhido como $o$ determinaria uma regulamentação de higiene racionalizada, [...] comportamentos sociais desse tipo não se improvisa nem nasce por geração espontânea (ESC. p. 118.).

Este processo de readaptação e reconhecimento dos novos parâmetros que passam a nortear as relações humanas, no ambiente carregado e desumano do manicômio, apresenta o corpo como um elemento fundamental para o estabelecimento de fronteiras, que definem quem somos nós e as dimensões do espaço criadas a partir das extensões do corpo em movimento.

A comparação da existência humana com a condição de animal é uma problemática que pode ser articulada com a experiência de corporeidade apresentada por Merleau-Ponty, na qual o corpo é natureza, na medida em que é do mesmo tecido das coisas do mundo, mas resguardando as devidas diferenças entre objeto e natureza. Assim, o corpo é uma metáfora da natureza, ou seja, o homem é uma idéia histórica e não uma espécie natural.

Os questionamentos suscitados pelas personagens do romance devem ser considerados como uma forma de desconstrução e posterior construção de novos conceitos que reabilitem as referências identitárias destruídas pela cegueira branca.

Tão longe estamos do mundo que não tarda que comecemos a não saber quem somos, nem nos lembrarmos sequer de dizer-nos como nos chamamos, para quê, para que iriam servir-nos os nomes, nenhum cão reconhece outro cão, ou se lhe dá a conhecer, pelos nomes que lhes foram postos, é pelo cheiro que se identifica e se dá a identificar, nós aqui somos uma outra raça de cães (ESC. p. 64.).

De todos os animais o homem difere, não apenas por ser o único ser que cuida do ser sendo, mas por ser o único ser cultural. Neste sentido o corpo do homem transcende a relação simplesmente biológica, ultrapassa a fronteira animal, institui níveis de ordem simbólica, transforma o mundo, cria e recria culturas. "A existência biológica está engrenada na existência humana, e nunca é indiferente ao seu próprio ritmo."13 Um sem o outro é animalidade pura, outro sem um é abstração que, só por ser abstração já pressupõe a existência e a imbricação de ambas. Em vista disso, alerta a mulher do médico: "se não formos capazes de viver inteiramente como pessoas, ao menos façamos tudo para não viver inteiramente como animais" (ESC. p. 119).

Para Merleau-Ponty o corpo é o traço que mais aproxima o homem do mundo natural, mas é por outro lado, também o que mais o distancia, visto que, no reino da pura animalidade,

\footnotetext{
${ }^{13}$ MERLEAU-PONTY, M. A Fenomenologia da Percepção. Op. cit. p. 221.
} 
o animal é seu corpo, se reduz a ele e às suas possibilidades naturais. O corpo do animal é 'escravo' da natureza. Enquanto que no reino do humano, o homem não apenas tem um corpo ao qual está atrelado e subjugado enquanto natureza, mas ele próprio é seu corpo.

O uso que o homem faz do corpo o coloca em contato direto com o mundo natural, como também com as situações emergidas do cotidiano, nas quais se dá o encontro com outras experiências. De modo que a própria organização do espaço, a descoberta da alteridade, e da subjetividade se dá pela abertura do corpo ao mundo no co-existir."Os cegos moviam-se como cegos que eram, às apalpadelas, tropeçando, arrastando os pés, não obstante, como se estivessem organizados, souberam repartir as tarefas eficazmente” (ESC. p. 91).

A necessidade de garantir a existência, em meio a um grande número de pessoas das mais diversas naturezas, conduz os cegos por um caminho de incertezas e instabilidade. Neste percurso, eles compreendem que a única certeza é a consciência existencial do corpo. "Não tardamos a perceber que nós, os cegos por assim dizer, não temos praticamente nada a que possamos chamar de nosso, a não ser o que levamos no corpo" (ESC. p. 216).

O corpo é único referencial do existir, na medida em que todos os significados de pertença vão se afogando no mar de cegueira. Então os cegos descobrem a importância do corpo como única mediação entre o ser e a dura realidade que estão a enfrentar.

Uma cena em que as mulheres seguem de mãos dadas para a camarata dos cegos malvados que as violentarão, segundo o próprio autor/narrador não há explicação a não ser a necessidade corporal de força do outro. Então questiona. "Porque vocês vão de mãos dadas, tinha calhado assim, há gestos que nem sempre se pode encontrar uma explicação fácil, algumas vezes nem a difícil pode ser encontrada” (ESC. p. 178).

Estas personagens não buscam só força no corpo uma da outra, mas uma compreensão primária e originária da dor. Nessa imagem está figurada a vivência da corporeidade através da qual o espaço humano se expressa. O corpo é o elemento referencial na construção e definição desse espaço, visto que:

As dimensões do espaço são criadas a partir das extensões do corpo, no desenvolvimento das experiências vividas, enquanto ação corporal interagindo no tempo e no espaço, como uma maneira de exprimir que meu corpo está no mundo. ${ }^{14}$

\footnotetext{
${ }^{14}$ MERLEAU-PONTY, M. Op.cit. p. 149ss
} 
Desse modo, a visão fenomenológica da corporeidade, possibilita a reflexão sobre o espaço vivido, pela expressão do corpo em presença e movimentação ${ }^{15}$. Por isso, faz-se necessário compreender que no ambiente restrito e desorganizado do manicômio, a organização urge como um passo fundamental para que se possa assegurar a sobrevivência, como também manter áreas recíprocas de movimentação e de comunicação um com os outros.

Aos poucos os cegos vão adquirindo essa consciência e se manifestam:

O mal é não estarmos organizados, devia haver uma organização [...] o corpo também é um sistema organizado, está vivo enquanto se mantém organizado, e a morte não é mais que o efeito de uma desorganização (ESC. p. 281).

No entanto, o processo de reconstrução e organização do espaço exige que alguns hábitos sejam adquiridos e cultivados. Nesta perspectiva Merleau-Ponty adverte:

O hábito exprime o poder que temos de dilatar nosso ser no mundo ou de mudar de existência anexando a nós novos instrumentos. Trata-se de um saber que está nas mãos, que só se entrega ao esforço corporal e que não se pode traduzir por uma designação objetiva. ${ }^{16}$

A aquisição do hábito torna-se imprescindível para os cegos que perderam todas as referências do mundo visível, onde o conhecimento, as práticas cotidianas e as relações humanas tinham por sustentáculo a visão.

A partir da cegueira todo o conhecimento e habilidades adquiridas quando ainda tinham olhos que viam, agora pouco servem. Novos significados devem ser apreendidos e isto é possível pelo constante esforço corporal que se deixa penetrar por uma nova significação das coisas e dos seres. O hábito tem esse poder de re-significar novas experiências. Através da apreensão motora, do sentido intencional, efetua-se o movimento táctil, conforme explica Merleau-Ponty (1994):

O fenômeno do hábito convida-nos a remanejar nossa noção do 'compreender' e nossa noção de corpo. Compreender é experimentar o acordo entre aquilo que visamos e aquilo que é dado, entre a intenção e a efetuação - e o corpo é nosso ancoradouro no mundo. ${ }^{17}$

No contexto da cegueira as personagens vivem uma realidade na qual todas as máscaras sociais deixam de ser importantes e necessárias. Os códigos sociais, assim como os nomes, os valores profissionais e categorias de classes passam a ter menor importância e se perdem em um universo onde os problemas que afligem os cegos, se resumem à necessidade

\footnotetext{
${ }^{15}$ Cf. AUGRAS, Monique Augras. O Ser da Compreensão: fenomenologia da situação de psicodiagnóstico. Petrópolis: Vozes, 1997. p. 41

${ }^{16}$ MERLEAU-PONTY, M. Op. cit. p. 199.

${ }^{17}$ Ibidem, Op. cit. p. 200.
} 
de sobrevivência. Para tanto, novos hábitos e códigos sociais devem ser estabelecidos e, sobretudo construídos. Esta nova apreensão de mundo depende fundamentalmente da motricidade do corpo, enquanto intencionalidade original.

Nesta perspectiva o corpo que habita o espaço e o tempo respectivamente, compreende as novas situações impostas pela cegueira coletiva, e expressa movimentos que possam se habituar a essa nova realidade, dando-lhe outras significações.

A mulher do médico olhava para os dois cegos que discutiam, notou que não faziam gestos, que quase não moviam o corpo, depressa haviam apreendido que só a voz e o ouvido tinham agora alguma utilidade, é certo que não lhes faltavam braços, que podiam brigar, lutar, vir às mãos, como se costuma dizer, mas uma cama trocada não valia tanto, todos os enganos da vida fossem como este, bastava que se pusessem de acordo (ESC. p. 101).

A amplitude dessa apreensão corporal como existência, nunca pode ser total, visto que "o espaço e o tempo têm horizontes indeterminados que encerram outros pontos de vistas." 18 Neste sentido, as experiências motoras do corpo enquanto síntese de tempo e espaço são movimentos sempre a recomeçar. No caso dos cegos, este processo é contínuo e adquirido a custa de muitos desencontros. "[...] Tateando, deu alguns passos e foi esbarrar com a parede. Estendeu um braço, estendeu o outro enfim encontrou a porta" (ESC. p. 97). A passagem dos cegos no manicômio foi uma experiência de constante aprendizagem, de re-signifcação das vivências passadas, presentes e futuras.

A retomada da visão no final do romance aponta para o recomeço de um processo de aprendizagem do ver que se iniciou com a cegueira. A partir das condições reais às quais as personagens foram submetidas, elas desenvolveram um novo ethos de vida, (ethos no sentido de habitar, morar, cuidar, criar costumes e hábitos) construindo uma nova percepção de si, do outro e da existência.

A discussão que se travou no decorrer deste texto foi na perspectiva de mostrar como o nosso olhar está condicionado e limitado pelo pensamento racionalista e materialista que norteia a sociedade da produção e do consumo na qual vivemos. Esta reflexão nos leva a pensar qual a diferença que impomos entre o ver e olhar, lembrando que, enquanto o ver está associado às coisas visíveis, o olhar está associado ao interior do ser, voltado para o sentido da co-existência, visando o encontro com o outro.

A leitura desse texto nos proporciona visualizar a desorganização humana, o caos e a crise dos valores mais básicos da sociedade. Neste labirinto, metáfora que se tornou comum

${ }^{18}$ Ibidem, Op. cit. p. 195. 
quando se fala em contexto urbano, irrompe a cena inusitada de uma trajetória de homens e mulheres cegos, que não deixaram de ter 'olhos límpidos e perfeitos', mas, que não sabem ver, ou já não podem ver.

Esta discussão não se esgota por aqui, uma vez que na sociedade atual diagnostica-se uma acentuada crise de valores e de cegueira humana, cotidianamente mostrada pelos meios de comunicação de massa. O filme, Ensaio sobre a Cegueira, lançado recentemente a partir do livro de Saramago e com expressiva vendagem de bilheteria, vem para nos lembrar mais uma vez 'Se podes olhar, vê. Se podes ver repara' frase com a qual José Saramago utiliza como epígrafe inicial do seu romance. Com este texto espero dar continuidade a esta reflexão que poderá ser ampliada nos setores acadêmicos e sociais, estendendo um convite a todos que desejam ver melhor, a se embrenhar nos labirintos do olhar perceptivo e sensível, na descoberta de si e da diferença. Como disse Fernando Pessoa: "Não basta abrir a janela para ver os campos e os rios. Não é bastante não ser cego para ver as árvores e as flores. É preciso também não ter filosofia nenhuma. Com filosofia não há árvores, há idéias apenas”.

\section{Referências}

AUGÉ, Marc. Não-Lugares: introdução a uma antropologia da supermodernidade. São Paulo: Papirus, 1994.

O Sentido dos Outros: atualidade da antropologia. Petrópolis: vozes, 1999. p. 71ss

AUGRAS, Monique. O Ser da Compreensão: fenomenologia da situação de psicodiagnóstico. Petrópolis: Vozes, 1997. p. 41.

BOSI, Alfredo. Fenomenologia do olhar. In: NOVAES, Adauto (Org.). O Olhar. São Paulo: Companhia da Letras, 1995. p. 66

BUZZI, R. Arcângelo. A Identidade Humana: modos de realização. São Paulo: Vozes, 2002.

CONNOR, Steven. Cultura Pós-moderna: introdução às teorias do contemporâneo. São Paulo: Edições Loyola, 1993. p. 51.

COSTA, M. de F. Batista. A Concepção de Corpo de Maurice Merleau-Ponty. Cadernos de Filosofia. UFPE, $n^{\circ}$ II, out/dez, 2000.

LYOTARD, Jean-François. A Fenomenologia. Lisboa: Edições 70 Ltda., 1999.

MERLEAU-PONTY, Maurice. Fenomenologia da Percepção. Tradução Carlos Alberto Ribeiro de Moura. São Paulo: Martins Fontes, 1994.

O Visível e o Invisível. São Paulo: Editora perspectiva, 2000. 
NOVAES, Adauto (Org.). O Olhar. São Paulo: Companhia da Letras, 1995.

PLATÃO. A República. Tradução Pietro Nassetti. São Paulo: Ed. Martin Claret, 2001. (Coleção a obra prima de cada autor).

ROUANET, Sérgio Paulo. O Olhar Iluminista. In: NOVAES, Adauto (Org.). O Olhar. São Paulo: Companhia da Letras, 1995. p, 135. 